\title{
Analisis Pertumbuhan Zakat Pada Aplikasi Zakat Online Dompet Dhuafa
}

\author{
Andi Hidayat ${ }^{1)}$, Mukhlisin ${ }^{2)}$ \\ ${ }^{1,2}$ Universitas Pamulang \\ *Email korespondensi: dosen02179@unpam.ac.id
}

\begin{abstract}
Technological developments are now penetrating the world of worship, for those who want to pay zakat even easier. A number of online applications including online shopping provide zakat payment features for muzakki. Looking at the data in the National Zakat Agency that the potential for zakat in 2019, based on the IIPZ association and Indonesia's zakat outlook, the potential for zakat is around Rp. 233.8 trillion divided into 5 objects of Zakat. In 2016 and 2017, zakat income was only around 6 trillion. The huge potential of zakat in Indonesia makes all zakat practitioners or zakat collection bodies have to find ways to maximize the potential for zakat and be able to create poverty in Indonesia. From efforts to manage zakat efficiently, Dompet Dhuafa as Amil zakat implements an online application system for zakat, the goal is to facilitate and improve zakat services for the better, with this online zakat application it is hoped that it will be able to absorb some of the existing potential zakat and help make it easier for people to pay zakat because limited distance and time.The purpose of this research in general is that the development and growth of zakat will increase with the existence of online zakat collection. In particular, to make it easier for muzakki in distributing zakat.This research uses qualitative research methods which are commonly referred to as naturalistic research methods because the research is carried out in natural conditions (natural setting), the research data sources are primary and secondary. The results and findings of the study are the growth of zakat from each year, either from the growth of zakat in the online zakat system or in the overall zakat income every year.
\end{abstract}

Keywords: Analysis, Zakat Online, Dompet Dhuafa

\begin{abstract}
Abstrak
Perkembangan teknologi kini merambah dunia ibadah, bagi mereka yang ingin membayar zakat pun semakin dipermudah. Sejumlah aplikasi online termasuk belanja online menyediakan fitur pembayaran zakat bagi muzakki. Melihat data yang ada di Badan Amil Zakat Nasional bahwa potensi zakat pada 2019,berdasarkan perhimpunan IIPZ dan outlook zakat Indonesia potensi zakat sekitar Rp. 233,8 Triliyun yang di bagi dalam 5 objek Zakat. Pada 2016 dan 2017 pendapatan zakat baru sekitar 6 trliyun. Potensi zakat yang sangatlah besar di Indonesia, membuat semua praktisi zakat ataupun badan penghimun zakat harus mencari cara bagaimana agar potensi zakat yang ada bisa maksimal dan mampu mengetaskan kemiskinan di Diindonesia.Dari upaya pengelolaan zakat yang efesien Dompet Dhuafa selaku Amil zakat menerapkan sistem aplikasi online untuk berzakat baik yang berbasis android dan Web, tujuannnya agar memudahkan dan meningkatkan pelayanan zakat menjadi lebih baik, dengan adanya aplikasi zakat online ini diharapkan mampu menyerap sebagian potensi zakat yang ada serta membantu memudahkan masyarakat membayar zakat karena terbatas jarak dan waktu.Tujuan penelitian ini secara umum adalah agar perkembangan dan pertumbuhan zakat semakin meningkat dengan adanya penghimpunan zakat melalui online. Secara khusus agar memudahkan para muzakki dalam menyalurkan zakat. Penelitian ini menggunakan metode penelitian kualitatif yang biasa disebut dengan metode penelitian naturalistik karena penelitianya dilakukan pada kondisi yang alamiah (natural setting), sumber data penelitian yaitu primer dan sekunder. Hasil dan temuan penelitian adalah adanya pertumbuhan zakat dari setiap tahun baik dari pertumbuhan zakat di system zakat online ataupuun di pendapatan zakat secara kseluruhan setiap tahun.
\end{abstract}

Kata Kunci: Analisis, Zakat Online, Dompet Dhuafa

Saran sitasi: Hidayat, A; \& Mukhlisin. (2020). Analisis Pertumbuhan Zakat Pada Aplikasi Zakat Online Dompet Dhuafa. Jurnal Ilmiah Ekonomi Islam, 6(03), 675-684. doi: http://dx.doi.org/10.29040/jiei.v6i3.1435

DOI: http://dx.doi.org/10.29040/jiei.v6i3.1435 


\section{PENDAHULUAN}

Zakat merupakan suatu ibadah yang memiliki nilai sosial yang tinggi. Selain itu, zakat juga memberi dampak positif terhadap kesejahteraan masyarakat. Bahwa dengan berzakat golongan kaya (muzakki) dapat mendistribusikan sebagian hartanya kepada golongan fakir miskin (mustahiq), maka terjadilah hubungan yang harmonis antara golongan kaya dan fakir miskin. Sehingga golongan fakir miskin dapat menjalan kegiatan ekonomi di kehidupannya. ( Ali Ridho, 2014).

Zakat merupakan salah satu instrumen yang digunakan untuk distribusi pendapatan dan kekayaan. Adanya zakat firah, zakat maal dan zakat profesi diharapkan dapat menekan tingkat ketimpangan yang ada diIndonesia, selain itu juga zakat dapat diandalkan sebagai salah satu mekanisme dalam mengatasi masalah kemiskinan yang terjadi di Indonesia, melalui program zakat produktif.( Yogi Citra P, 2015).

Di zaman modern sekarang ini pengelolaan zakat harus diupayakan dan dirumuskan dengan sedemikian rupa, sehingga dapat dikelola secara baik. Para pengelola telah merumuskan pengelolaan zakat berbasis manajemen. Pengelolaan zakat berbasis manajemen dapat dilakukan dengan asumsi dasar bahwa semua aktivitas yang terkait dengan zakat dilakukan secara professional. Pengelolaan zakat secara professional, perlu dilakukan dengan saling keterkaitan antara berbagai aktivitas yang terkait dengan zakat. Dalam hal ini, keterkaitan antara sosialisasi, pengumpulan, pendistribusian atau pendayagunaan, serta pengawasan.

Dengan penduduk Indonesia begitu besar dan mayoritas muslim, pengelolaan zakat dituntut untuk lebih baik dan menyeluruh agar memudahkan para muzakki dalam menunaikan zakat, bahkan Pengelolaan zakat sudah di sahkan oleh negara tahun 1999. Dengan tanda bukti adanya Undang-Undang No 38/1999 tentang Pengelolaan Zakat. Kemudian diperbarui pada tahun 2011 yaitu Undang-Undang No 23/2011.( Yusuf . W, 2015).

Mengacu pada potensi pengelolaan zakat, Baznas mengatakan ada sekitar Rp. 233,8 Triliyun rupiah potensi zakat di Indonesia dan baru terserap sekitar 6 Triliyun rupiah, jelas ini menjadi pekerjaan rumah bagi lembaga amil zakat untuk terus meningkatkan pelayanan dan inovasi dalam pengelolaan zakat.

Perkembangan teknologi komunikasi dapat dengan mudah di pahami oleh masyakarat. Pada dasarnya arus perkembangan teknologi akan menentukan dinamika hidup manusia saat ini dan manusia akan mengikuti alur dinamika tersebut. Jaringan media yang paling luas saat ini adalah internet, yang hampir semua orang mampu mengaksesnya dengan mudah. Jaringan ini harus dimanfaatkan demi menjangkau akses- akses terkecil dan efesiensi waktu untuk penjualan suatu produk atau pelayanan sebuah jasa, salah satunya pengumpulan zakat dengan potensi yang begitu luas maka diperlukan aksebiliti yang begitu inovatif dan mudah.

Membaca arus teknologi informasi yang begitu cepat salah satu lembaga amil zakat yang terkenal dompet dhuafa meresponnya dengan inovasi dan pelayanan zakat melalui pelayanan zakat online, yang mana pelayanan zakat online ini bertujuan untuk memudahkan para mustahik untuk menunaikan zakat dimanapun dan kapanpun.

Dari pemaparan diatas penulis melihat harus adanya platpom baru bagi penghimpunan zakat yang efektif dan menambah solusi layanan dengan mengandalkan teknologi, dompet dhuafa disini hadir melihat fenomena gaya hidup yang berubah dari offline ke online, maka menghadirkan layanan zakat online adalah hal tepat bagi usaha pertumbuhan zakat di Indonesia.

Guna mendukung penelitian ini, peneliti mencari penelitian terdahulu yang relevan, namun peneliti belum menemukan penelitian yang sejenis namun ada beberapa penelitian yang hampir mendekati dianataranya :

Khairul Rijal dan Nilawati dalam Jurnal I Economic : A Researc Journal on Islamic Economics, yang berjudul Potensi Pembayaran Zakat Secara Online dan Offline Serta Realiasi Dana Zakat Di Indonesia : menyatakan bahwa potensi pembayaran zakat secara online dan offline serta realisasi dana zakat di Indonesia pada periode 2012 - 2017 mengalami peningkatan, dengan meningkatnya penduduk yang wajib zakat, dan pendapatan perkapita. Namun selain ada peningkatan pembayaran zakat masih rendah karena rata-rata penerimaan zakat hanya di kisaran $0,2 \%$ pertumubahannya jadi perlu upaya terus menerus agar penerimaan zakat terus tumbuh. (Khairul Rijal dan Nilawati, 2019)

Winda Dkk, JEBI : Jurnal Ekonomi dan Bisnis Islam, Judul Implementasi Teknologi Informasi dan Komunikasi Dalam Zakat Untuk Meningkatkan Kesejahtraan Masyarakat Miskin : Menyatakan bahwa untuk mendukung aktivitas optimalisasi pengumpulan zakat harus dibuat basis teknologi informasi agar lebih efektif dan cepat, sepertinya adanya WA center, Twitter, FB, IG, serta produk digital lainnya lainnya, 


\section{Jurnal Ilmiah Ekonomi Islam, 6(03), 2020, 677}

bukan hanya data muzakki yang bisa dengan mudah terkumpul namun data mustahiq pun bisa di lihat denagn basis data teknlogi infromasi tadi. (Winda Dkk, 2018) .

KM. Munir 'Sistem aplikasi online zakat LAZ Nurul Hayat Cabang Semarang, yang dinamakan aplikasi "Zakat Kita"yang mana aplikasi ini digunakan untuk memudahkan para muzakki menunaikan zakat ( KM. Munir : 2017),

kemudian data yang lain menyebutkan ditengah Pandemi covid 19 masyarakat cenderung membayar zakat dengan online, misalnya pertumbuhan zakat online digital di platform Gopay dari Gojek meningkat tajam bahkan akan menjadi peluang bagi pertumbuhan zakat kedepan. ( Republika : 2020).

Ascara dan Diana Y mengungkapkan ada 3 faktor yang menyebabkan tidak optimalnya pengumpulan zakat di Indonesia, pertama rendahnya kesadaaran muzakki, serta rendahnya kepercayaan muzakki pada organisasi lembaga zakat, kedua,basis zakat hanya terkonsentrasi pada jenis zakat tertentu seperti zakat fitrah dan zakat profesi. Ketiga, masih rendahnya terobosan terobosan untuk mengali zakat lebih optimal.( Ascara dan Diana Y. 2018).

Dalam penelitian diatas membahas kontribusi yang sama dengan menekankan aspek optimalisasi zakat melalui media teknologi, agar potensi zakat yang ada bisa terkumpul dengan maksimal serta memudahkan para pengelola zakat untuk mendata muzakki dan mustahik secara menyeluruh. Namun ada pendekatan dan temuan hasil yang beda dengan peneliti tulis, adapun fokus penelitian yang diteliti pada petumbuhan zakat diportal layanan online hhtp//donasi.dompetdhuafa.org.

\section{KAJIAN TEORI}

\section{Pengertian Analisis}

Menurut kamus besar bahasa Indonesia analisis mempunyai pengertian penyelidikan terhadap suatu peristiwa guna mengetahui keadaan yang sebenarnya. ( KBBI Online, 2019).

Analisis adalah sikap atau perhatian terhadap sesuatu benda, fakta, dan fenomena, sehingga mampu menguraikan menjadi bagian-bagian serta mengenal kaitan bagian tersebut dalam keseluruhan. Kemudian analisis dapat diartikan yaitu kemampuan memecahkan sesuatu materi atau informasi menjadi bagian-bagain kecil sehingga mudah dipahami. (Vimila Mutihana, 2017).
Menurut pengertian diatas analisis mempunyai arti penguraian suatu pokok secara sistematis dalam menentukan bagian hubungan antara bagian secara menyeluruh untuk memperoleh pengertian dan pemahaman yang tepat.

\section{Pengertian Zakat}

Zakat menurut bahasa artinya suci dan subur, sedangkan menurut istilah ialah mengeluarkan sebagian dari harta benda atas perintah Allah SWT sebagai shadaqah wajib kepada mereka yang telah ditetapkan menurut syarat - syarat yang telah ditentukan oleh hukum Islam ( Moh. Syafii, 2013).

Kemudian zakat diartikan juga al-barakatu yang mempunyai arti keberkahan, ath- thaharatu yang memiliki arti kesucian, al-namu yang mempunyai arti pertumbuhan dan perkembangan, dan ash-shalahu yang memiliki arti keberesan. Sedangkan zakat ditinjau dari segi istilah terdapat banyak ulama' yang mengemukakan dengan redaksi yang berbeda-beda, akan tetapi pada dasarnya mempunyai maksud yang sama, yaitu bahwa zakat itu adalah bagian dari harta dengan persyaratan tertentu, yang Allah SWT mewajibkan kepada pemiliknya untuk diserahkan kepada seseorang yang berhak menerimanya, dengan persyaratan tertentu pula ( Dindin.H, 2012 )

Menurut Yusuf Qardhawi zakat adalah sebagian harta tertentu yang dikeluarkan menurut perintah Allah SWT dan diserahkan kepada orang tertentu.( Ahmad Furqon, 2015 ).

Zakat merupakan rukun Islam yang ketiga yang mana zakat merupakan kewajiban bagi setiap muslim apabila mempunya harta yang sudah mencukupi.( Hamidy Thalib dkk, 2017 ).

Seorang mukmin apabila ia mengeluarkan zakat akan dapat membersihkan jiwanya dari sifat kikir dan dosa dia akan mendapatkan berkah dalam hartanya keluarga dan peninggalannya , serta akan membersihkan dia dari harta yang haram.

Dapat disimpulkan pengertian zakat adalah sesuatu yang diberikan seseorang sebagai hak Allah SWT, kepada yang berhak menerima seperti fakir ,miskin, sesuai ketentuan yang ada dalam agama Islam. 
Dalil dan Hukum Tentang wajib hukumnya bagi setiap mukmin yang mempunyai harta menurut ketentuan yang ditetapkan oleh syariat Islam, berikut dalil dan hukum tentang zakat:

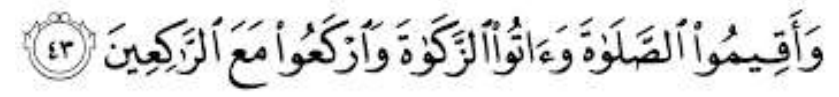

Artinya . dan dirikanlah shalat, tunaikanlah zakat dan ruku'lah beserta orang-orang yang ruku' ( $\mathrm{Al}$ Baqarah ayat 43)

Ayat ini memerintahkan bagi umat Islam untuk mengerjakan salat dan disusulkan dengan perintah menunaikan zakat, intisari dari ayat ini bagaimana bentuk keimanan kita sebagai muslim dengan menunaikan ikatan kepada Allah dengan salat dan tidak lupa juga dibarengi hubungan dengan manusia dengan perantara zakat.

Dalam ayat lainnya Allah SWT berfirman yang artinya :

Jika mereka bertaubat dan mendirikan sholat dan menunaikan zakat, Maka berilah kebebasan kepada mereka untuk berjalan. Sesungguhnya Allah Maha Pengampun lagi Maha Penyayang. ( At-Taubah ayat 5).

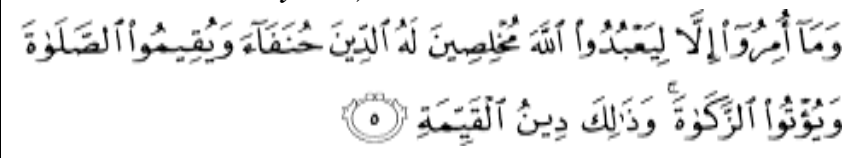

Artinya : Padahal mereka tidak disuruh kecuali supaya menyembah Allah dengan memurnikan ketaatan kepada-Nya dalam (menjalankan) agama yang lurus, dan supaya mereka mendirikan shalat dan menunaikan zakat; dan yang demikian Itulah agama yang lurus. ( Albayinah ayat 5 ).

Disamping Al- Quran ada juga hadis yang menyatakan kewajiban berzakat diantaranya:

Islam dibangun di atas lima perkara: bersaksi bahwa tidak ada ilah (sesembahan) yang berhak disembah melainkan Allah dan Muhammad adalah utusan-Nya; menegakkan shalat; menunaikan zakat; menunaikan haji; dan berpuasa dibulan Ramadhan ( Mutafaq alaih). Dari Ibnu Abbas ra. bahwa Nabi Shallallaahu 'alaihi wa Sallam mengutus Mu'adz ke negeri Yaman --ia meneruskan hadits itu-- dan didalamnya (beliau bersabda): "Sesungguhnya Allah telah mewajibkan mereka zakat dari harta mereka yang diambil dari orang-orang kaya di antara mereka dan dibagikan kepada orangorang fakir di antara mereka." Muttafaq Alaihi dan lafadznya menurut Bukhari.

\section{Macam- Macam Zakat}

Zakat terbagi kedalam 2 bagian yaitu zakat Fitrah dan zakat mal.

\section{Syarat Wajib Zakat}

1) merdeka

2) Islam

3) baligh berakal

4) Kondisi harta dapat berkembang

5) Sampai Nisab

6) Sudah mencapai 1 tahun

7) Tidak ada Hutang. ( Wahbah. Z, 2011).

\section{Harta yang Wajib di Zakati}

1) Barang Dagangan

2) Emas dan Perak

3) Hasil Pertanian dan Buah-buahan

4) Hewan ternak

5) Hasil tambang

Ada beberapa sumber lain dari ahli fiqih tentang harta yang wajib dizakati, seperti pendapat Sayyid sabiq, Wahbah Zuhaili,Hasbi Assydiqi, serta Abdurahman al -Jaziri, namun semuanya sepakat 5 diatas sudah mencakup kesepakatan bersama (Dimyati, 2017)

\section{Orang Yang berhak menerima Zakat}

1) Orang fakir

2) Orang Miskin

3) Para Amil zakat

4) Orang yang Muallaf

5) Budak

6) Gharim ( orang yang mempunyai hutang banyak)

7) Fisabillah

8) Ibnu Sabil. ( M. Haris Riyaldi 2017).

\section{Pengertian Sistem Aplikasi Online}

Sistem didefinisikan sebagai suatu kesatuan yag terdiri dari dua atau lebih komponen yang berinteraksi untuk mencapai suatu tujuan. Sistem adalah jaringan kerja dari prosedur- prosedur yang saling berhubungan berkumpul bersama-sama untuk melakukan suatu kegiatan atau menyelesaikan sasaran tertentu. seperangkat komponen yang saling berhubungan dan berfungsi mengumpulkan, memproses, dan mendistribuikan informasi untuk mendukung pembuatan keputusan dan pengawasan dalam organisasi.( Yusran.B dan Ririn, 2016).

Secara istilah sistem dipakai dalam berbagai macam cara yang luas sehingga sangat sulit untuk mendefeinisikan atau mengartikannya sebagai suatu 
pernyataan yang merangkum seluruh pengunaannya, hal ini menyebabkan pengertian sistem tergantung pada latar belakang siapa yang mendefinisikannya. (Ridho.S , 2018).

Kemudian Fanny Andalia dan Eko budi.( 2015) mengatakan ada dua kelompok pendekatan dalam mendefinisikan system, ada yang menekankan pada komponen atau elemennya, diantaranya : Pendapat pertama menekankan system pada pada komponen nya yang mana " sistem adalah kumpulan dari elemenelemen yang berinteraksi untuk mencapai suatu tujuan tertentu. Pendapat kedua menekankan sistem pada prosedur yaitu system adalah suatu jaringan kerja dari prosedur-prosedur yang saling berhubungan, berkumpul bersama-sama untuk melakukan kegiatan sasaran tertentu.

\section{Unsur- unsur Sistem}

Untuk dapat dikatakan apakah itu system maka harus mencakup 5 unsur sebagai berikut :

1) Adanya kumpulan objek

2) Adanya hubungan atau interaksi antara unsurunsur atau elemen.

3) Terdapat sesuatu yang mengikat unsur tersebut menjadi satu kesatuan.

4) Berada pada lingkungan yang utuh

5) Terdapat tujuan berasama sebagai hasil akhir. (Arifin, 2017).

Aplikasi online terdiri dari dua suku kata pertama aplikasi yang mempunyai pengertian alat bantu untuk mempermudah dan mempercepat prosese pekerjaaan dan bukan beban bagi pengunannya. Jadi aplikasi online adalah suatu penerapan sistem untuk mempermudah dan memenuhi pekerjaan tertentu dengan mengunakan media jaringan internet.

\section{METODOLOGI PENELITIAN}

Penelitian ini dilakukan di Dhompet Dhuafa. Pemilihan lokasi dilakukan dengan dasar beberapa pertimbangan diantaranya adalah Dhompet Dhuafa yang merupakan LAZ yang menerapkan inovasi pembayaran zakat dengan online, serta sudah menjalin beberapa kerjasama dengan layanan digital.

Penelitian ini menggunakan metode penelitian kualitatif yang biasa disebut dengan metode penelitian naturalistik karena penelitianya dilakukan pada kondisi yang alamiah (natural setting) (Sugiyono, 2016) Sedangkan menurut meleong penelitian kualitatif adalah penelitian yang bertujuan memahamkan tentang fenomena yang terjadi pada subjek penelitian misalnya, perilaku, persepsi dan motivasi. (Muhammad Nazir, 2005). Metode penelitian kualitatif adalah metode penelitian yang digunakan untuk meneliti pada kondisi alamiah dan peneliti menekankan pada makna.

Sumber data penelitian yaitu primer dan sekunder, Data primer merupakan data yang diperoleh peneliti dari sumber (langsung dari informan) yaitu dari Dompet Dhuafa, data sekunder adalah data yang diperoleh dari sumber kedua, sumbernya didapatkan dari website Dompet Dhuafa, Media Sosial Dompet Dhuafa.

Teknik pengumpulan data merupakan langkah yang paling strategis dalam penelitian, karena tujuan utama dari penelitian adalah mendapatkan data. Tanpa mengetahui teknik pengumpulan data, maka peneliti tidak akan mendapatkan data yang memenuhi standar data yang ditetapkan. Dalam penelitian ini teknik pengumpulan data dengan observasi, wawancara dan dokumentasi.

\section{HASIL PENELITIAN}

\section{Analisis Pertumbuhan Zakat Dengan Adanya zakat Online di Dompet Dhuafa.}

Dompet Dhuafa adalah sebuah lembaga yang berdiri pada tahun 1993, lembaga yang bergerak dalam bidang layanan zakat dan kemanusiaan. Dompet Dhuafa fokus berkhidmat dalam perbedayaan kaum dhuafa dengan pendekatan budaya, program dan layanan Dompet dhuafa mencakup beberapa bidang, yaitu pilar pendidikan,pilar ekonomi,pilar kesehatan, pilar sosial, dakwah dan budaya.

Selain itu Dompet Dhuafa sebagai pelopor amil zakat modern mencoba lebih inovatif dan kreatif dengan memunculkan beberapa layanan yang dapat membantu mengembangkan lembaga itu sendiri. Seiring dengan perkembangan zaman dan teknologi menciptakan sebuah inovasi adalah suatu yang harus dilakukan oleh suatu lembaga maupun sebuah perusahaan, karena harus menyesuaikan dengan perkembangan mayarakat yang ada pada saat ini. Masyarakat modern ini lebih banyak paham tentang teknologi dan lebih memilih suatu yang mudah dalam kegiatanya sehari-hari, seperti mudah dalam melakukan belanja online, memilih transportasi online, dan begitu juga dalam hal pembayaran zakat, infaq, maupun sedekah, pastinya memilih sesuatu yang mudah dan terpercaya. 


\section{Jurnal Ilmiah Ekonomi Islam, 6(03), 2020, 680}

Dalam hal pembayaran zakat perlu adanya pembaharuan dan inovasi dalam system pembayaran, sesuai dengan kaidah Islam relevan sepanjang zaman maka pembayaran zakatpun bisa di modifikasi melalui online. Adapun zakat adalah kewajiban bagi setiap muslim maka harus di fasilitasi dengan baik dan mudah,posisi zakat sendiri mempunyai peran strategis bagi kemajuan umat dengan adanya zakat rasa kemanusiaan dan perhatian sesama muslim terbangun sehingga akan tercipta harmonsasi dalam bingkai agama dan bangsa.

Di Indonesia sendiri zakat di atur dalam UUD tahun 2011 N0. 23, yang mana UUD tersebut mengatur pengelolaan zakat secara professional, mulai dari pengumpul zakat, menjaring muzakki,pendistribusian serta pelaporan, tentu dengan adanya UUD ini lembaga zakat harus lebih bisa mengoptimalkan potensi ZISWAF yang ada di Indonesia.

Selain berkomitmen dengan UUD di atas setiap lembaga pastinya memiliki cara tersendiri dalam hal mendapatkan donatur maupun muzzaki, ada yang sering melakukan promosi baik secara online maupun lewat, pamflet, majalah bulanan dan selebaran. Dompet Dhuafa juga banyak melakukan promosi baik secara online baik dengan membuat media sosial seperti facebook, twitter, instagram dan menciptakan aplikasi online pembayaran zakat maupun melalui selebaran, hal tersebut merupakan langkah positif dalam hal penarikan donatur maupun muzzaki. Selain promosi hal lain yang dilakukan oleh Dompet Dhuafa adalah meningkatkan sebuah pelayanan kepada setiap muzzaki maupun donatur.

a. Membuat Kampanye iklan melalui jaringan media sosial untuk berzakat dan donasi di Dompet Dhuafa.

b. Melakukan jemput zakat dan donasi yaitu layanan penarikan zakat, infaq, maupun sedekah yang dilakukan oleh Dompet Dhuafa dengan cara mendatangi setiap orang yang ingin melakukan ZIS.

c. Mengunakan sistem aplikasi online pembayaran zakat dan donasi yang tertera di web http:/donasi.dompetdhuafa.org., QR Kode, ECommerce, M-Banking dan lainnya yang bertujuan mempermudahkan para donator atau muzzaki dalam pembayaran ZIS.

Adanya layanan tersebut pastinya bertujuan untuk pengembangan Dompet Dhuafa itu sendiri, layanan yang baik dan menarik akan membuat masyarakat menjadi tertarik dan mempunyai keinginan atau dorongan untuk melakukan donasi di Dompet Dhuafa, dan tujuan lain adalah agar berkembangnya pendapatan ZIS di Dompet Dhuafa dengan adanya layanan dan program-program yang dimiliki oleh Dompet Dhuafa , salah satunya adalah layanan tentang pembayaran zakat, infaq dan sedekah online.

Dompet Dhuafa merupakan pelopor pembayaran zakat online, hal ini dilakukan karena lembaga ini melihat adanya peluang dalam hal sistem online yang di era modern ini lebih disukai masyarakat. Dengan menciptakan inovasi ini adakah dampak yang diberikan terhadap Dompet Dhuafa sendiri yang akan dibahas dengan menunjukan data-data berupa pendapatan ZIS periode 2016-2017-2018 di bawah ini. Dan untuk penekanan pertumbuhan pembayaran zakat online tersebut berada pada laporan pendapatan ZIS.

Table 1. Hasil Pendapatan ZISWAF dan lainnya di Dompet Dhuafa Tahun 2016.

\begin{tabular}{|c|c|}
\hline Sumber Pendapatan & $\begin{array}{c}\text { Jumlah yang } \\
\text { didapatkan }\end{array}$ \\
\hline Zakat & 143.342 .000 .000 \\
\hline Infak & 36.736 .000 .000 \\
\hline Infak terikat & 25.942 .000 .000 \\
\hline Kurban & 29.470 .000 .000 \\
\hline Kemanusiaan & 11.807 .000 .000 \\
\hline Wakaf & 10.812 .000 .000 \\
\hline Lainnya & 2.829 .000 .000 \\
\hline Total & 260.937 .000 .000 \\
\hline
\end{tabular}

(Sumber : Publikasi.dompetdhuafa.org.)

Hasil di atas merupakan total keselurahan pendapatan Laz Dompet Dhuafa Tahun 2016 dari 161.330.000 donatur muzakki, presentase pendapatan dana ZIS yaitu untuk zakat 55\%, infak 14\%, infak terikat $10 \%$, kurban $11 \%$, kemanusiaan $5 \%$, wakaf 4 $\%$, lainnya $1 \%$.

Table 2. Hasil Pendapatan ZISWAF dan lainnya di Dompet Dhuafa Tahun 2017.

\begin{tabular}{|c|c|}
\hline Sumber Pendapatan & $\begin{array}{c}\text { Jumlah yang } \\
\text { didapatkan }\end{array}$ \\
\hline Zakat & 145.858 .000 .000 \\
\hline Infak & 33.037 .000 .000 \\
\hline Infak terikat & 29.115 .000 .000 \\
\hline Kurban & 27.197 .000 .000 \\
\hline Kemanusiaan & 15.903 .000 .000 \\
\hline Wakaf & 20.004 .000 .000 \\
\hline Lainnya & 2.375 .000 .000 \\
\hline Total & 273.471 .000 .000 \\
\hline
\end{tabular}

(Sumber : Publikasi.dompetdhuafa.org.) 


\section{Jurnal Ilmiah Ekonomi Islam, 6(03), 2020, 681}

Hasil di atas merupakan total keselurahan pendapatan Laz Dompet Dhuafa Tahun 2017 dari 46.709.000 donatur muzakki, presentase pendapatan dana ZIS yaitu untuk zakat 53\%, infak $12 \%$, infak terikat $11 \%$, kurban $10 \%$, kemanusiaan $6 \%$, wakaf 7 $\%$, lainnya $1 \%$.

Table 3. Hasil Pendapatan ZISWAF dan lainnya di Dompet Dhuafa Tahun 2018.

\begin{tabular}{|c|c|}
\hline Sumber Pendapatan & $\begin{array}{c}\text { Jumlah yang } \\
\text { didapatkan }\end{array}$ \\
\hline Zakat & $156,000.000 .000$ \\
\hline Infak & $35,530.000 .000$ \\
\hline Infak terikat & $27,320.000 .000$ \\
\hline Kurban & $36,010.000 .000$ \\
\hline Kemanusiaan & $34,070.000 .000$ \\
\hline Wakaf & $34,450.000 .000$ \\
\hline Lainnya & $1,840.000 .000$ \\
\hline Total & $325,200.000 .000$ \\
\hline
\end{tabular}

(Sumber : Publikasi.dompetdhuafa.org.)

Hasil di atas merupakan total keselurahan pendapatan Dompet Dhuafa Tahun 2018 dari 57.139.000 donatur muzakki, presentase pendapatan dana ZIS yaitu untuk zakat 48\%, infak $10.9 \%$, infak terikat $8.4 \%$, kurban $11.07 \%$, kemanusiaan $11.09 \%$, wakaf $10.6 \%$, lainnya $0,22 \%$.

Pada tahun 2016 sistem aplikasi pembayaran zakat online mulai gencar digunakan oleh Dompet Dhuafa, hal tersebut merupakan inovasi yang dilakukan oleh Dompet Dhuafa dalam bidang pembayaran zakat yang memiliki banyak tujuan, selain mempermudah juga sebagai pengenalan kepada masyarakat banyak tentang Dompet Dhuafa sebagai Lembaga Amil Zakat yang modern dan mengikuti perkembangan teknologi. ( Adi Kurniawan, Wawancara : 2020).

\section{Gambaran Sistem Aplikasi Zakat Online Dompet} Dhuafa.

Langkah Pertama membuka aplikasi zakat online Dompet Dhuafa donasi.dompetdhufa.org. dan klik “ zakat"

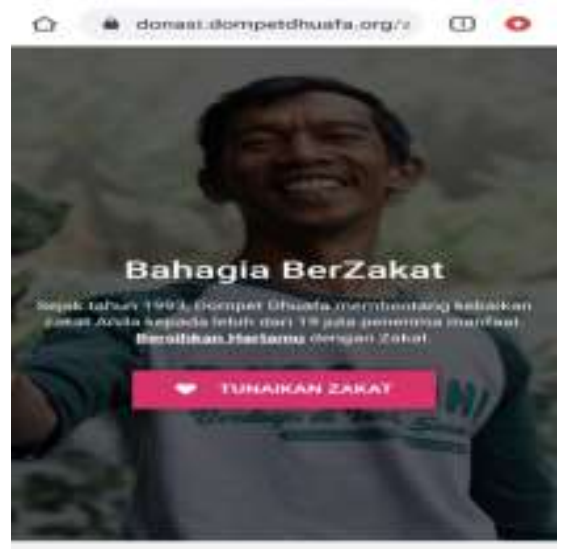

Langkah kedua akan muncul tampilan " Pilihan Donasi" Zakat Mal, Zakat Pengahasilan,serta Nominal yang akan di donasikan.

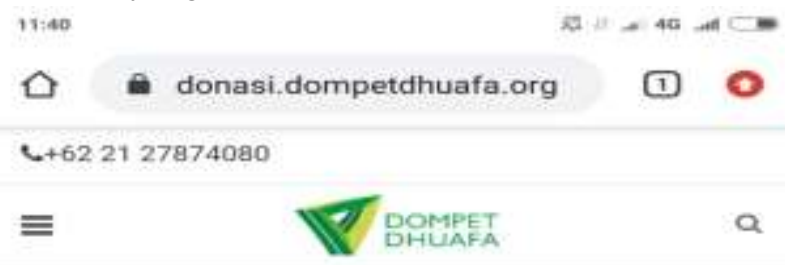

Selamat datang di portal donast, donasi aman dan mudah

Pilihan Donasi
Jenis Donasi *
Zakat
Pengkhususan donasi
Zakat Penghasilan
Keterangan donasi
*silahkan pilih *
Jumlah (Rp.) *
50ooo
Minimai: 10000

Profil Donatur

Sapaan *

Bapak

Nama Lengkap *

Muhlisin

Email *

muhlisin12@gmail.com

Telepon / HP *

085412645214

Contoh: 085717527494

$[+]$ Tampilkan informasi tambahan

Sesuai dengan peraturan perpajakan di indonesia, untuk mendapatkan manfaat sebagai pengurang Penghasilan Kena Pajak (PKP) sesuai keputusan Dirjen Pajak No. PER11/PJ/2017. Kami mernelurkan informasi tambahan mengenai profis diri Anda

Silahkan pilih metode pernbayaran

Langkah ketiga akan muncul profil Donator dan sesudah itu pilih metode pembayaran 


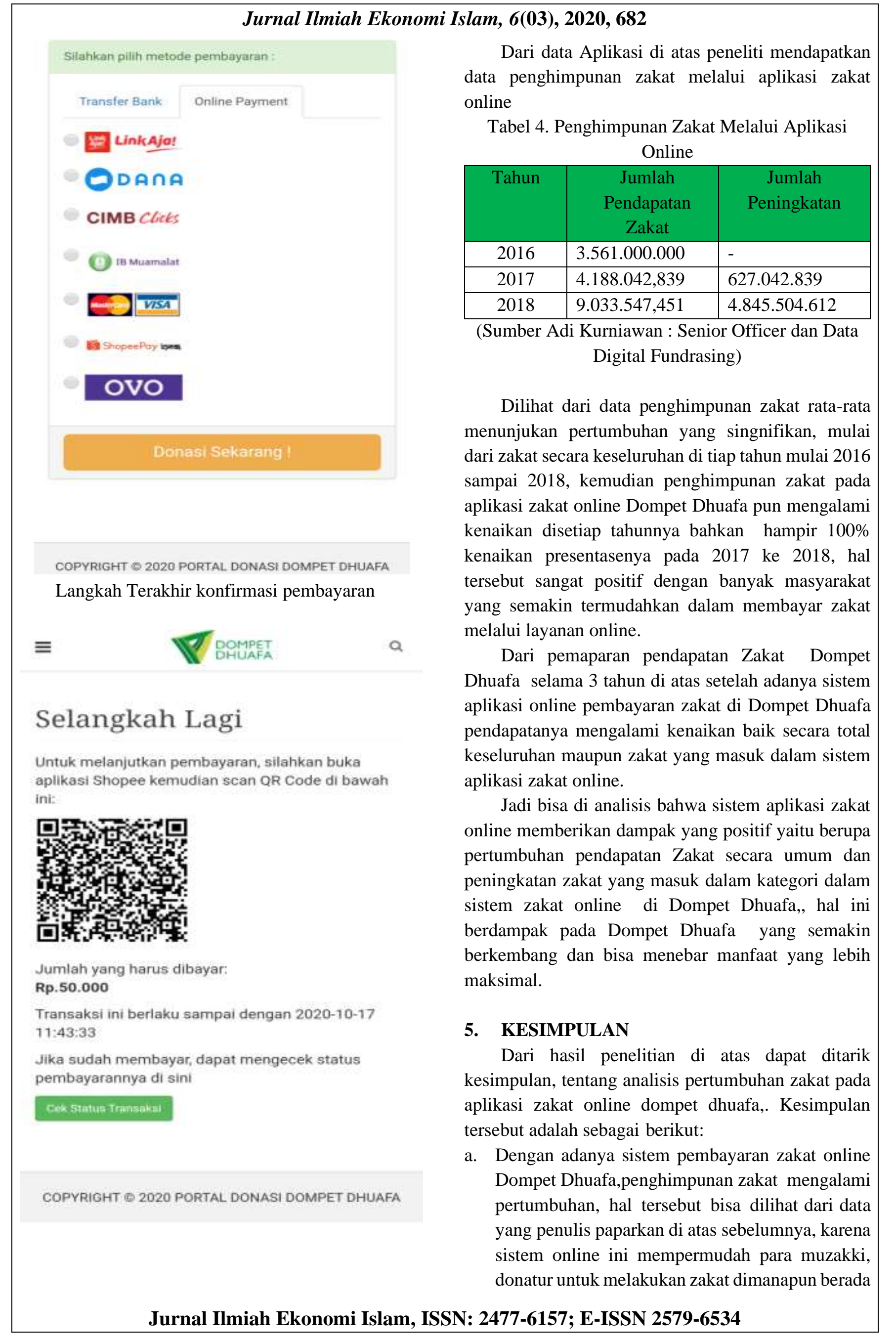




\section{Jurnal Ilmiah Ekonomi Islam, 6(03), 2020, 683}

dan kapanpun ingin melakukanya. Sistem pembayaran zakat online ini juga merupakan sebuah terobosan baru dalam hal pembayaran zakat dan hal tersebut memberikan dampak yang baik bagi pertumbuhan zakat di Dompet Dhuafa.

\section{UCAPAN TERIMA KASIH}

Penulis mengucapkan terima kasih tidak terhingga kepada pihak yang telah membantu penulis menyelesaikan penelitian ini, ucapan terima yang utama saya ucapkan kepada Direktorat Riset dan Pengabdian Masyarakat, Direktorat Bidang Penguatan Riset dan Pengembangan, Badan Riset dan Inovasi Nasional ( RISTEK - BRIN), Bapak Yayasan Universitas Pamulang, Bapak Rektor, LPPM, Dosen Agama, Dosen Prodi Matematika serta Istri tercinta,ibu dan kakak.saya ucapkan terima kasih sebesar-besarnya.

\section{REFERENSI}

Andalia Fanny dan S. Budi Eko, 2015, Pengembangan Sistem Informasi Pengelolaan Data Pencari Kerja Pada Dinas Sosial dan Tenaga Kerja Kota Padang, Jurnal Ilmiah Komputer dan Informatika, Vol 4 No 2 Oktober, 93

Arifin, 2017, Perancangan Rental Kamera Online Berbasis Web Interaktif, Bandung.

Ascarya dan Diana Y, 2018, Analisis Rendahnya pengumpulan zakat di Indonesia dan Alternative Serta S olusinya, Jurnal bank Indonesia, Working paper September, 1

A. Yusran dan N. Rahmadani Ririn, 2016, Analisis dan Perancangan Sistem Informasi Manajemen Keuangan Rumah Sakit Berbasis Web ( Studi Kasus Pada RSU Daerah Sawerigading Kota Palopo Prov. Sulsel, Jurnal Teknosains, Vol 10, Nomor 2. Juli Desember, 153

Dimyati, 2017, Urgensi Zakat produktif di Indonesia, Al Tijary, Jurnal ekonomi Islam dan Bisnis Islam, Vol 2, No 2, 192

Effendi Usman, 2014, Asas Manajemen, Jakarta: RajaGrafindo Persada.

Furqon, 2015, Ahmad. Manajemen Pengelolaan Zakat, Semarang: CV Karya Abadi Jaya.

Hafidhuddin Didin, 2012, Zakat Dalam Perekonomian Modern,Jakarta: Gema Insani,

Kurniawan Adi, 2020, Wawancara,Senior Officer dan Data Digital Fundrasing ,20 Agustus
Misbahul Munir Kukuh, 2017, Aanalisis Pertummbuhan Zakat Pada Sistem Aplikasi Online "Zakat Kita" ( Studi LAZ Nurul Hayat cab. Semarang). Semarang : Skripsi Fakultas Ekonomi dan Bisnis Islam, Uin Walisongo.

Muntihana Vimila, 2017 , Analisis dan Perancangan Sistem Informasi Berbasis Web dan Android Pada Klinik Gigi Lisda Medica di Kabupaten Bulukumba Sulsel, Makasar : Skripsi Fakultas Sains dan Teknologi, Uin Alaudin Makasar.

M.Republika.co.id, 2020, Kini Bayar Zakat Lebih Mudah Dengan Gopay, diakses 12 Juli

Nazir Muhammad, 2005, Metode Penelitian, Jakarta : Ghalia Indonesia

Pratama Yoghi Citra, 2015, Peran Zakat dalam Penanggulangan Kemiskinan (Studi Kasus : Program Zakat Produktif Pada Badan Amil Zakat Nasional), The Journal of Tauhidinomics Vol. 1 No. 1, 94

Ridho Ali, 2014, Zakat Dalam Persfektif Ekonomi Islam, Jurnal Al-Adl Vol. 7 No. 1, Januari, 119

Rijal Khairul dan Nilawati, 2019, Potensi Pembayaran Zakat Secara Online dan Offline Serta Realiasi Dana Zakat di Indonesia, Jurnal I - Economic : A Researc Journal on Islamic Economics,, Vol 5 No 2, 116-131

Riyaldi M. Haris, 2017 , Kedudukan dan prinsip pembagian Zakat dalam Mengatasi permasalahan kemiskinan ( Analisis pandangan Yusuf Qardawi ) Jurnal persfektif ekonomi Darusalam, Vol 3 No 1, 19

Safrudin, 2020.staf Publikasi dan Pusat Data DomPet Dhuafa,Senin 15 Juni .

Saputra Ridho, 2018, Pengembangan Sistem Rental Kamera Online, Jurnal Pengembangan Teknologi Informasi dan Ilmu Komputer Vol 2 No 6, 221

Saputra Suhar, 2012. Metode Penelitian: Kuantitatif, Kualitatif dan Tindakan. Bandung : PT Refika Aditama

Sugiyono, 2016. Metode Penelitian Kuantitatif, Kualitatif dan R n D. Bandung : PT Alfabaet

Syafii Mohammad, 2013, Fiqih Islam, Semarang : PT Toha Putra.

Thalib Hamidy dkk , 2017, Model pengelolaan Zakat Untuk Mengatasi Kemiskinan dikota Bima, Maqdis : Jurnal kajian Eko Islam, Vol 2 no 1 Januari-Juni, 25

Wibisono Yusuf, 2015, Mengelola Zakat Indonesia, Jakarta: Prenadamedia Group. 
Jurnal Ilmiah Ekonomi Islam, 6(03), 2020, 684

Winda, 2018, Implementasi Teknologi Informasi dan Komunikasi Dalam Zakat Untuk Meningkatkan Kesejahtraan Masyarakat Miskin, JEBI : Jurnal Ekonomi dan Bisnis Islam, Vol 3 No 2 Juli Desember, 227-236
Zuhaili Wahbah, 2011, Fiqih Islam wa Adilatahu, Terjemah Abdl Hayyi, Jakarta: Gema Insani. 